\title{
COMPACT OUTPUT FILTER FOR SWITCHING FREQUENCY ELIMINATION AT THE PLC LINAC NEW MAGNET POWER SUPPLY*
}

\author{
S. C. Kim, K. M. Ha, J. Y. Huang, and J. H. Choi \\ Pohang Accelerator Laboratory, POSTECH San 31, Hyoja-dong, Pohang 790-784, Korea
}

\section{Abstract}

Pohang Accelerator Laboratory Linac magnet power supply (MPS) has been upgraded for the stable beam injection and $4^{\text {th }}$ generation light source research, in 2006. MPSs are developed as compact configuration by using four quadrant switching scheme with power MOSFET. In case of $10 \mathrm{~V},+/-10 \mathrm{~A}$ bipolar output operation, main circuit is operated as one or three quadrant, and in case of $50 \mathrm{~V}, 50 \mathrm{~A}$ unipolar output operation, main circuit is operated as parallel one quadrant. Switching frequency of MOSFET switch is above than $40 \mathrm{kHz}$. MPS consists of main power board, control power board, regulator board and CPU board. The size of each board has $100 \mathrm{~mm}$ width and $250 \mathrm{~mm}$ depth. Main power board made of fourquadrant MOSFET switch, driver and output filter. Output filter must be perfectly eliminating switch frequency and have compact size. In this paper, we report on development and characteristics of compact output filter of the new MPS for PAL linac.

\section{INTRODUCTION}

The high-performance magnet power supplies for particle accelerator system require a second-order lowpass filter to reduce the output current ripple within specifications. Because of the large time constant, the load magnet provides very little damping to the secondorder output filter. [1] Many switching power converters have applications that require very low high-frequency noise and ripple on the output. A single-stage filter which meets the requirements can become very large and impractical, especially for boost and buck-boost converter which have pulsating output currents. Unfortunately, a second LC filter gives up to $180^{\circ}$ additional phase delay in the control-to-output transfer function, and it can make the system unstable if improperly designed. [2] The new MPS of the Linac has been developed by full-bridge fourquadrant scheme. To develop compact MPS, main power conversion is developed as PCB board of $100 \mathrm{~mm} \mathrm{x}$ $250 \mathrm{~mm}$ size. Main power PCB board is made of MOSFET switch, driver and output LC filter. Therefore, output LC filter must be compact size and eliminate noise from MOSFET switch. In this paper, we report on development and characteristics of compact output filter of the new MPS for PAL linac.

\section{BASIC CONCEPT OF NEW MPS FOR PAL LINAC}

Full-bridge four-quadrant DC/DC converter scheme is

\footnotetext{
*Work supported by by the MOST, Korea

" schkim@postech.ac.kr
}

selected as MPS topology of the PAL Linac. This type converter is able to operate bipolar or unipolar output mode according to PWM switching method. Table 1 shows the specifications of the PAL Linac MPS. The required maximum output current is $\pm 10 \mathrm{~A}$ and $50 \mathrm{~A}$, and output stability is $\pm 100 \mathrm{ppm}$ and $\pm 50 \mathrm{ppm}$ in the bipolar and unipolar MPS, respectively.

Table 1: Specifications of MPS for upgraded one

\begin{tabular}{|c|c|c|c|}
\hline & Bipolar & Unipolar & unit \\
\hline $\begin{array}{c}\text { Size } \\
\text { (W x H x D) }\end{array}$ & $435 \times 135 \times 450$ & $435 \times 178 \times 450$ & $\mathrm{~mm}$ \\
\hline Input & $1 \phi 220 \mathrm{~V}$ & $3 \phi 30 \mathrm{~V}$ & $\mathrm{~V}$ \\
\hline Output & $\pm 10 / 20$ & $50 / 50$ & $\mathrm{~A} / \mathrm{V}$ \\
\hline \multirow{2}{*}{ Stability } & $\pm 50 \mathrm{ppm}$ & $\pm 20 \mathrm{ppm}$ & $<1$ hour \\
\cline { 2 - 5 } & $\pm 100 \mathrm{ppm}$ & $\pm 50 \mathrm{ppm}$ & $>10$ hours \\
\hline Resolution & \multicolumn{2}{|c|}{$>40$} & $\mathrm{bit}$ \\
\hline \multicolumn{2}{|c|}{ Switch frequency } & $<5$ & $\mathrm{kHz}$ \\
\hline \multicolumn{2}{|c|}{ Output Filter Cut-off freq. }
\end{tabular}

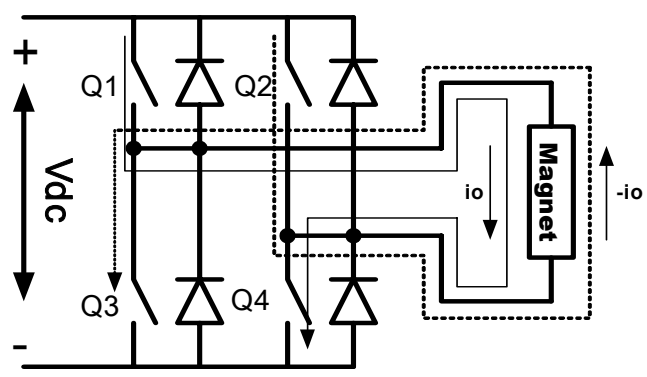

Figure 1: Bipolar output operation of full-bridge four quadrant DC/DC converter.

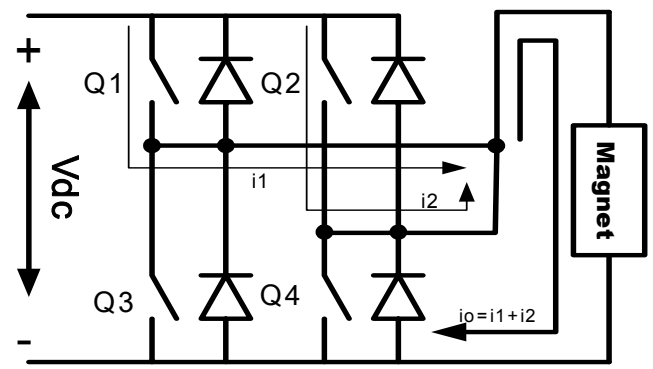

Figure 2: Unipolar output operation of full-bridge fourquadrant DC/DC converter.

Fig 1 and Fig 2 show the basic circuit diagram of bipolar and unipolar MPS operations of a full-bridge fourquadrant DC/DC converter. In Fig 1, output current flows 
to a load as positive or negative direction $\left(\mathrm{i}_{\mathrm{o}}\right.$ or $-\mathrm{i}_{\mathrm{o}}$ ) by on or off its contact point of two-switch pair (Q1-Q4 or Q2Q3). In Fig 2, output current flows to the load as only positive direction $\left(i_{1}\right.$ or $i_{2}$ ) by on or off its contact point of two-switch leg (Q1-Q3 or Q2-Q4). In this case, if twoswitch legs are parallel simultaneously, the current $\left(i_{1}+\right.$ $\mathrm{i}_{2}$ ) to the load is double the amount of current in Fig 1. Clean DC current should be supplied to magnet for minimized beam effect by power supply. At Fig 1 and 2, switching noises from main switch occurred at load, and the output filter needs between main switch and load. Size of main power PCB is only $100 \mathrm{~mm}$ width and $250 \mathrm{~mm}$ depth and included main circuit and LC output filter. Therefore, LC output filter must develop as compact size.

\section{LC OUTPUT FILTER OF PAL LINAC NEW MPS}

Two-stage LC filter is used for the new MPS of the PAL Linac. The configuration of the output filter is twostage LC and RC damping filter. Fig 3 shows circuit diagram of the output filter. In fig $3,1^{\text {st }}$ stage LC filter $\left(\mathrm{L}_{11}, \mathrm{~L}_{12}, \mathrm{C}_{11}, \mathrm{C}_{12}\left(\mathrm{C}_{1}\right)\right)$ must be arranged within $95 \mathrm{~mm} \mathrm{x}$ $70 \mathrm{~mm}$ at main power module $\mathrm{PCB}$ and $2^{\text {nd }}$ stage $\mathrm{LC}$ filter $\left(\mathrm{L}_{21}, \mathrm{~L}_{22}, \mathrm{C}_{21}, \mathrm{C}_{22}\right)$ must be arranged within $86 \mathrm{~mm} \times 110$ $\mathrm{mm}$ as other PCB.

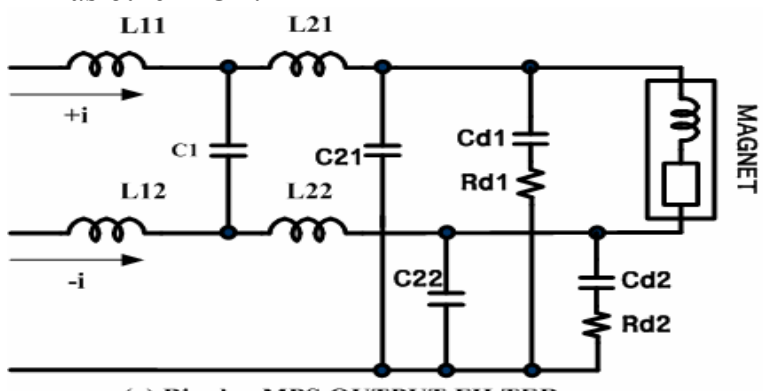

(a) Bipolar MPS OUTPUT FILTER

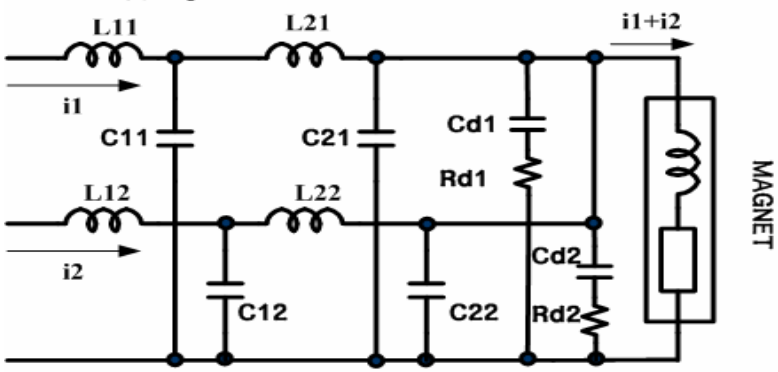

(b) Unipolar MPS OUTPUT FILTER

Figure 3: Filter circuits of the PAL Linac new MPS

\section{Component selection}

Key design points of two-stage LC output filter design are control bandwidth, switching frequency of the power supply, and cut-off frequency of the filter. $1^{\text {st }}$ filter cut-off frequency must be more about five times than that of control bandwidth, and $2^{\text {nd }}$ filter cut-off frequency must be closely control bandwidth. Switching frequency must be more than ten times compare with control bandwidth. Control bandwidth is decided in accordance with MPS application.

\section{Inductance of the output filter}

The first consideration item is inductor choice in filter design. Inductor value controls the amount of ripple current that the capacitor. Inductance is calculated by Eq. 1.

$$
L=\frac{V_{\text {out }} \times\left(V_{\text {in }} \max -V_{\text {out }}\right)}{V_{\text {in }} \times f_{\text {sw }} \times I_{\text {out }} \times K}
$$

Here, $\mathrm{K}=0.3$ of the output current. Desirable value of the inductor might to have a very small value of inductance greater than $30 \%$ for high current application. Recommend inductance value is several ten- $\mu \mathrm{H}$. In output filter, an inductor is important factors to make small size and low-cost of power supply. Normally inductor has above two-times size and above three times cost compare with capacitor.

\section{Capacitance of the output filter}

The capacitance of the output filter should be high value for cut-off at low frequency. And capacitor ESR (Equivalent Series Resistance) not only contributes to the ESR zero but also contributes significantly to the damping factor of the filter. The drawback of a high ESR capacitor is that to have low ripple and good transient response, the output filter needs to have lower ESR values. [4]

\section{Inductors and capacitors for the filter}

$1^{\text {st }}$ stage LC-filter is arranged at main power module PCB. The inductor of $1^{\text {st }}$ and $2^{\text {nd }}$ stage filter used the same core. R-material ferrite core (R-44022-EE) of Magnetics companies is selected as the core of the inductor. Switching frequency of the MPS is $50 \mathrm{kHz}$. Therefore, winding wire must consider skin effect to occur on high frequency switching. $0.2 \mathrm{~mm}$ thickness x $26 \mathrm{~mm}$ copper foil is used as wire. Winding is 25 turns. An inductor has $72 \mathrm{~cm}^{3}(4.0 \times 4.0 \times 4.5)$ volume, and DC resistance is 20 $\mathrm{m} \Omega$. Inductance valu of $1^{\text {st }}$ and $2^{\text {nd }}$ filter is controlled according to gap thickness. An capacitor is selected with PCB mountable type. WIMA MKS4 $15 \mu \mathrm{F}$ capacitor is adopted as a filter capacitor. The capacitor ESR is 10 $\mathrm{m} \Omega$. Table 2 describes output filter parameters. Fig 4 shows fabricated output filter.

Table 2: Output filter parameters

\begin{tabular}{|c|c|c|c|}
\hline & inductance & capacitance & $\begin{array}{c}\text { Cut-off } \\
\text { frequency }\end{array}$ \\
\hline $\begin{array}{c}1^{\text {st }} \text { stage } \\
\text { filter }\end{array}$ & $120 \mu \mathrm{H}$ & $\begin{array}{c}30 \mu \mathrm{F} \\
(15 \mu \mathrm{F} \times 2)\end{array}$ & $3.0 \mathrm{kHz}$ \\
\hline $\begin{array}{c}2^{\text {nd }} \text { stage } \\
\text { filter }\end{array}$ & $60 \mu \mathrm{H}$ & $\begin{array}{c}45 \mu \mathrm{F} \\
(15 \mu \mathrm{F} \times 3)\end{array}$ & $2.6 \mathrm{kHz}$ \\
\hline
\end{tabular}



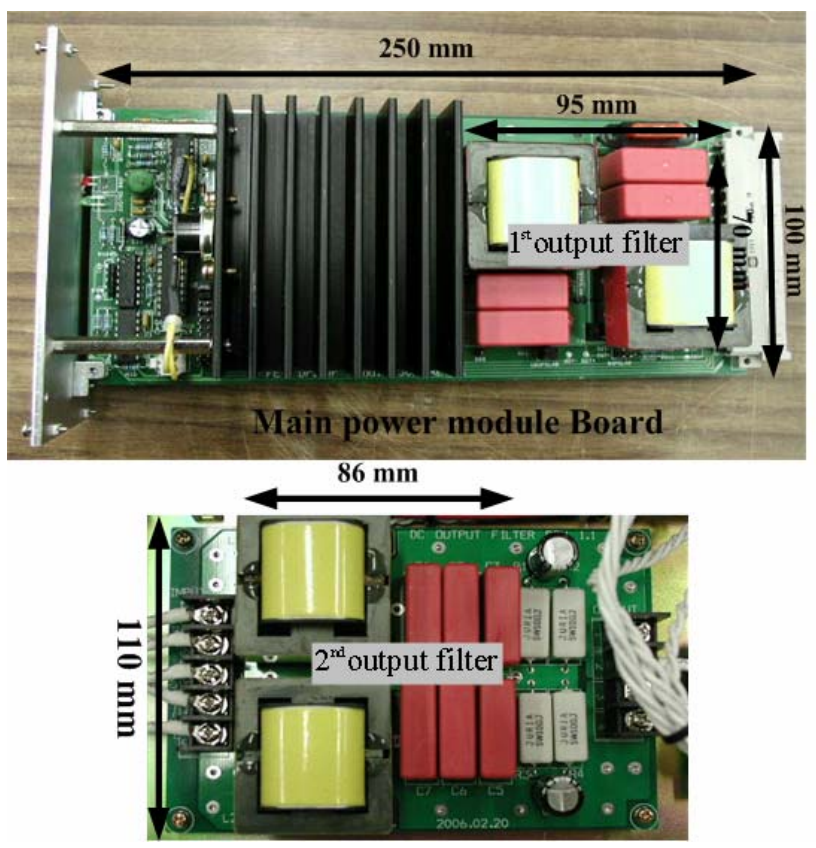

Figure 4: Fabricated output filter

\section{Frequency characteristics and effect of the output filter}

A dynamic signal analyser, Stanford Research SR780, was used for frequency characteristics measurement of filter and output current. Total cut-off frequency of the output filter is measured about $1.5 \mathrm{kHz}$. Attenuation is below than $-70 \mathrm{~dB}$ at MPS switching frequency. Therefore, generated any noise from PS is completely eliminated and clean DC current may be supplied to the magnet. Fig 5 shows frequency characteristics of output filter measured from bipolar and unipolar MPS, respectively. Fig 6 shows effect of output filter at output current. After filter output current not included any noise from MPS.

\section{Output stability of PAL Linac new MPS}

The measured points were short and long-term stability, and frequency characteristics that are important factors for determining PS performances. For the measurements of performance, Keithley2700 6.5digit digital multi-meter (DVM) is used. Long-term stability is keeping in \pm 40 ppm and $\pm 6.5 \mathrm{ppm}$ during 19 hours, and short-term stability is keeping in $\pm 15 \mathrm{ppm}$ and \pm 2 ppm during 1 hour for the bipolar and unipolar MPS, respectively.

\section{SUMMARY}

The new compact MPS with a full-bridge 4-quadrant $\mathrm{DC} / \mathrm{DC}$ converter scheme has been developed for PAL Linac. In order to maintain easily, standardized PCB was used for both bipolar and unipolar mode in the power supply. Configuration of the output filter is adopted 2stage LC filter. Output filter is developed as compact size. Output filter is perfectly eliminated generated noise from power supply. Therefore, clean output DC current can be supplied to the magnets. Long-term stability is keeping in $\pm 40 \mathrm{ppm}$ and $\pm 6.5 \mathrm{ppm}$ during 19 hours, and short-term stability is keeping in \pm 15 ppm and \pm 2 ppm during 1 hour for the bipolar and unipolar MPS, respectively.

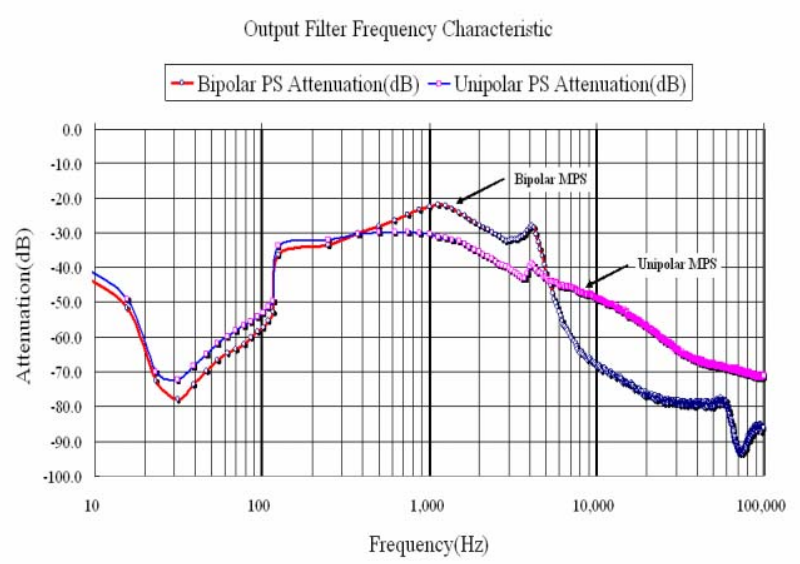

Figure 5: Frequency characteristics of the output filters
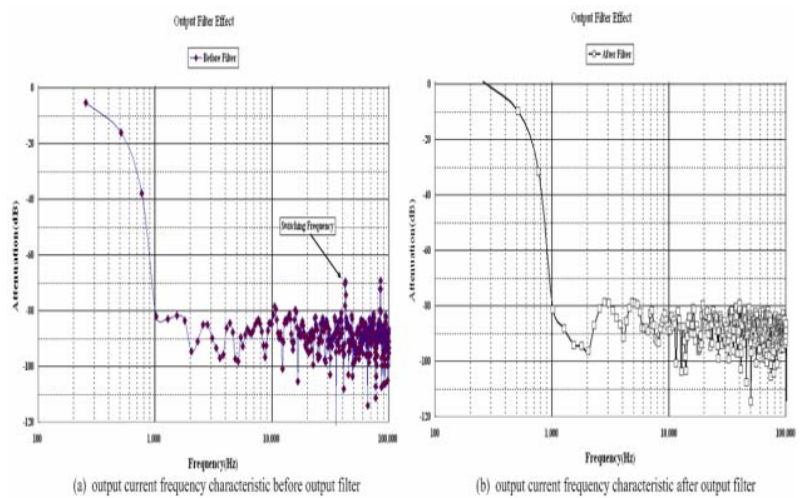

Figure 6: filter effect at output current

\section{REFERENCES}

[1] M. R. Pavan Kumar and J. M. S. Kim, "Capacitor current feedback for output filter damping in switched-mode magnet power supplies", IEEE transactions on magnetics, vol.30, no. 4, July 1994, pp. $1778-1781$

[2] Raymond B. Rdley, "Secondary LC Filter Analysis and Design Techniques for Current-Mode-Controlled Converters", IEEE transactions on power electronics, vol. 3, no. 4, Oct. 1988, pp. 499- 507

[3] Hoyerby, M.C.W.; Andersen, M.A.E., "Envelope tracking power supply with fully controlled 4th order output filter", Applied Power Electronics Conference, APEC'06., Twenty-First Annual IEEE, 19-23 March 2006, pp.993-1000

[4] Sipex application note ANP22, Filter Design in continuous conduction mode

[5] S. C. Kim, K. M. Ha, etc, "New Magnet Power Supply for PAL Linac", EPAC2006 proceeding, pp. 2685-2 